\title{
Experimental and calculated approach to the study of deformation and strength characteristics of elastoviscoplastic materials by direct impact method
}

\author{
V.G. Bazhenov ${ }^{1}$, M.S. Baranova ${ }^{1, a}$, E.V. Nagornykh², and D.L. Osetrov ${ }^{2}$ \\ ${ }^{1}$ Research Institute of Mechanics Lobachevsky State University of Nizhni Novgorod, Pr. Gagarina 23, \\ 603950 Nizhni Novgorod, Russia \\ ${ }^{2}$ Lobachevsky State University of Nizhni Novgorod, Pr. Gagarina 23, 603950 Nizhni Novgorod, Russia
}

\begin{abstract}
It is proposed to develop experimental and calculated approach to the study of the strength characteristics of elastoviscoplastic materials in a non-uniform strain-stress state. Integral characteristics (forces, displacements and displacement speed) of the deformation process of hat-shaped specimens in tension are determined by a direct impact method, and their strain - stress states are determined by numerical solution of the axisymmetric problem. The results of experimental and theoretical study of the deformation and failure of hat-shaped specimens in the presence of stress concentrators are obtained.
\end{abstract}

\section{Introduction}

Originally vertical gas-gun testing stands solved the problem of metal forming technologies. The results of these tests are not very suitable for the mathematical simulations of deformation due to roughness measurements and methods of processing the results of the experiment. Refinement methodologies occurred after implementation to measure the resistance forces Hopkinson bar in 1914. Kolsky proposed split bar and data processing in 1924. This methodology is most popular in the last 50 years in dynamic tests of materials for compression and tension [1-3]. The methodology allows to implement a range of strain rates $5 * 10^{2}-5 * 10^{3} 1 / \mathrm{s}$ at moderate degrees of deformation. Range of strain rates further narrowed due to the lack of impact energy, implemented through the transmission rod on the specimen for fracture in tests of metals and alloys in tension to failure. Modification of the split Hopkinson bar by removing the transmission bar and the direct impact of striker of the same diameter as the measuring rod for the test specimen was proposed for increasing realized experimentally strain rates above $5 * 10^{3} 1 / \mathrm{s}$ and strains. This methodology combines the advantages of a split Hopkinson bar method and a direct impact on the accuracy of measurements of displacement rod ends. But it requires a fairly large length striker, which imposes restrictions on the technical possibilities of its application. To achieve greater impact energy in a direct impact method striker is selected significantly larger diameter than the measuring rod. The direct impact method which realized on the vertical gas-gun testing stand allows to increase the strain rates and strains, but also to cover the range of low strain rates up to $10^{1} 1 / \mathrm{s}$ at the impact energy sufficient to fracture of the hat-shaped specimens in tension testing. Klepaczko suggested to use optical

\footnotetext{
${ }^{a}$ Corresponding author: mari.baranova18@gmail.com
}

gauges for measuring the velocity of the striker end which contacts with the specimen in 2001 [4]. Methodologies of experimental results (build diagrams of deformation by a direct impact) are investigated and underdeveloped compared to the procedure for the Kolsky methodology for split Hopkinson bar. Processing of the results of tests of the hat-shaped specimens in tensile conducted under the assumption of homogeneity of stress-strain state in the test portion of the specimens. What is impracticable because of the difficulties in preparing the specimens with slit-like ports and not widely used and further develop.

In Russia there is no practical realization of direct impact on the vertical gas-gun testing stand for construction of dynamic diagrams of deformation and strength characteristics of the study materials in tension. Those who have previously been established, do not meet the accuracy requirements for use in the mathematical simulation of deformation and strength assessment of modern constructions.

\section{Influence of the form striker in the process of impact tension of hat-shaped specimens}

In order to study the possibilities of increasing the pulse width while maintaining the length of the striker numerical simulations of various forms of the impactor (cylindrical, with slotted opening and balls) is done.

The problem is solved in an axisymmetric formulation. $\mathrm{Z}$ - axis of symmetry. Various types of striker (transfer ring and cylinder, transfer ring and cylindrical striker with slotted opening) are simulated. Striker and transfer ring move with an initial velocity $\mathrm{V}_{0}=3 \mathrm{~m} / \mathrm{s}$.

The gas-gun testing stand for tensile testing by direct impact method (Fig. 10) contains the following elements:

This is an Open Access article distributed under the terms of the Creative Commons Attribution License 4.0, which permits unrestricted use, distribution, and reproduction in any medium, provided the original work is properly cited. 


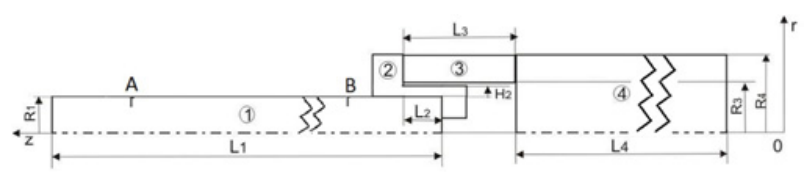

Figure 1. Scheme of gas-gun testing stand for testing by direct impact method.

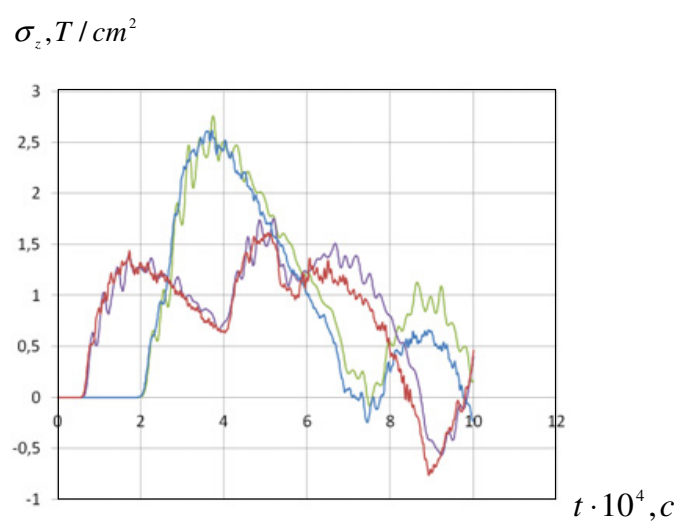

Figure 2. Stresses from gauges in sections $A$ and $B$ of the measuring rod.

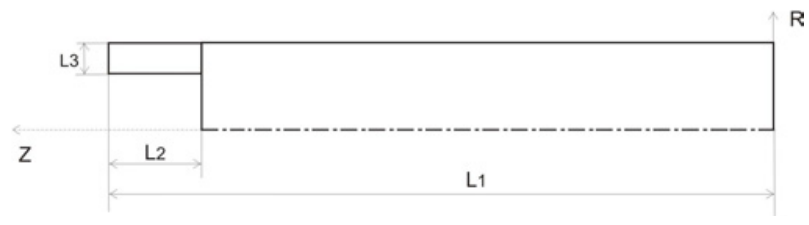

Figure 3. Cylindrical striker.

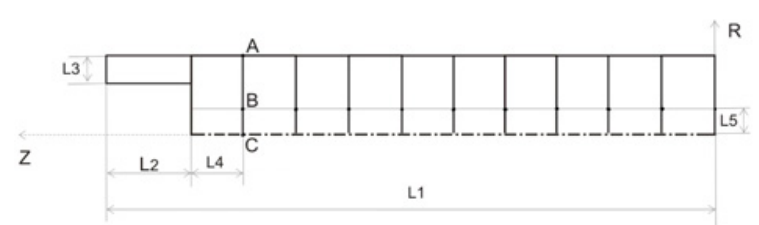

Figure 4. Cylindrical striker with slotted opening.

supported measuring rod (marked 1), hat-shaped specimen (2), transfer ring (3), striker (4).

Geometric parameters of the elements of gas-gun testing stand are described in [5].

Comparing the results of calculations using "Dynamics2" [6] and LS-DYNA is done. Figure 2 shows stresses from gauges in sections A and B of the measuring rod (Fig. 1), located at a distance of $105.8 \mathrm{~cm}$ and $30.8 \mathrm{~cm}$ from the impacted end of measuring rod on the same finite element mesh in the initial impact velocity of $4.52 \mathrm{~m} / \mathrm{s}$. Red and blue marked stresses in the gauges in the section B and A (Fig. 2) using "Dynamics-2." Purple and green - using "LS-DYNA".

The calculation results are in good agreement, which confirms the accuracy of the "Dynamics-2."

Two forms (cylindrical and cylindrical with slotted opening) of strikers are modelled. Figures 3-4 show forms of strikers.

$\mathrm{L}_{1}=0,3585 \mathrm{ML}_{2}=0,05 \mathrm{M} \mathrm{L}_{3}=0,0148 \mathrm{M} \mathrm{L}_{4}=0,0303$ $\mathrm{M}, \mathrm{L}_{5}=0,023 \mathrm{M}$.

$\mathrm{BC}$ is a contact surface.

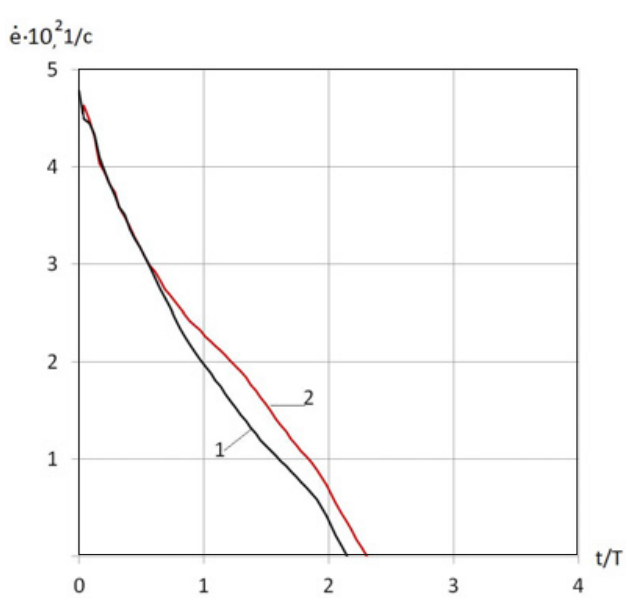

Figure 5. Strain rate.

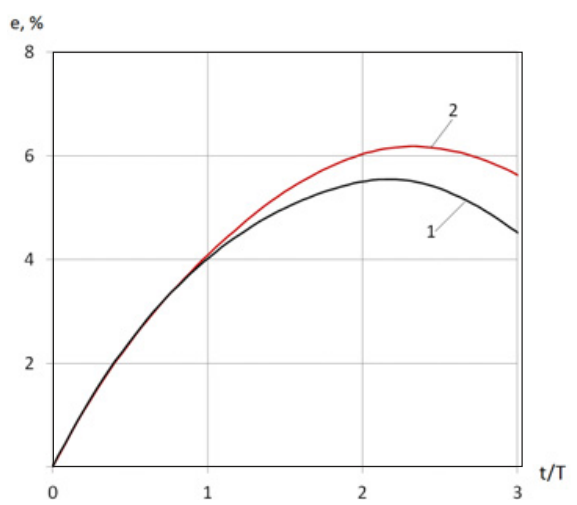

Figure 6. Strain.

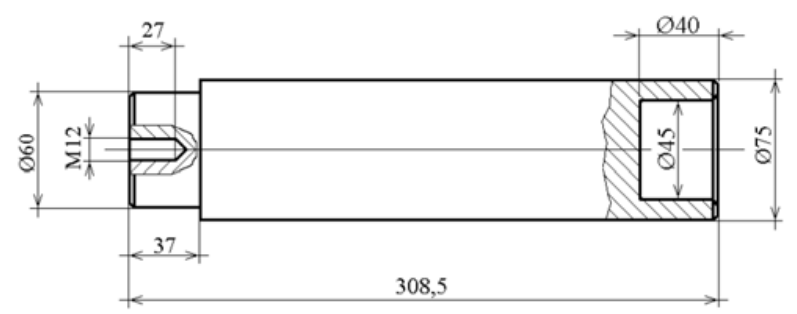

Figure 7. Striker.

$\mathrm{Z}$ - axis of symmetry.

Figures 5-6 show strain rate and strain for two types of strikers.

1 - cylindrical striker with a tube, 2 - striker with slotted opening.

Striker with pits gives some effect of increasing strain and strain rate due to stretching of the pulse due to the dispersion of waves.

In [7] the numerical simulation of cylindrical workpieces using standard hammer and hammer with a filler in the form of steel balls. Based on the above studies, it is concluded that the complexity of form striker does not have much effect. Striker was made from practical considerations, ease of manufacture and use in the experiments. It is shown in Fig. 7. 


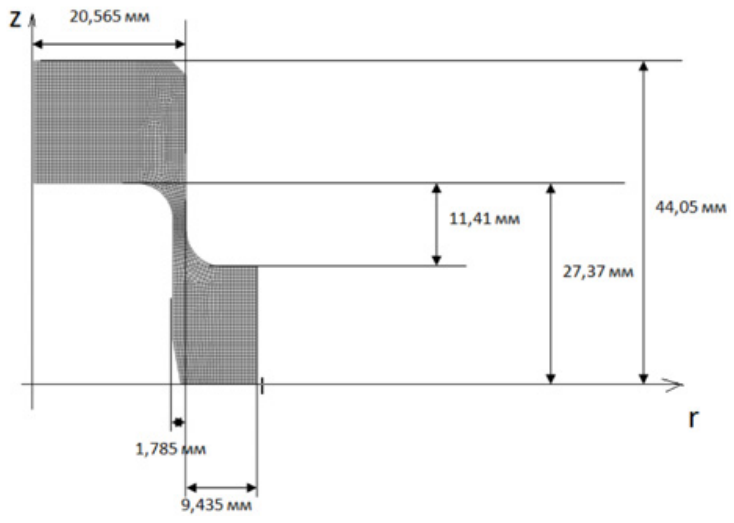

$\mathrm{Z}$ - axis of symmetry.

Figure 8. Hat-shaped specimen.
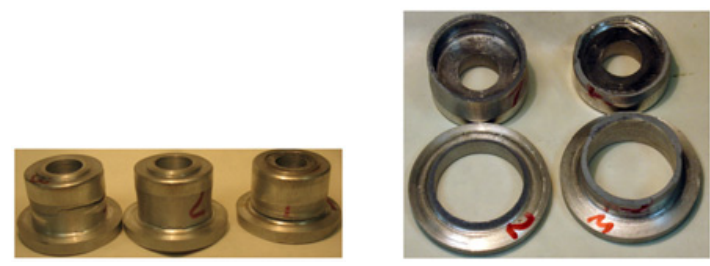

Figure 9. Hat-shaped specimens after testing.

The application of one-dimensional model of the wave process for the recovery of the experimental parameters of loading and deformation of the hat-specimen are given in [5].

\section{Investigation of the stress-strain state in the hat-shaped specimens}

Experiment on tensile of hat-shaped specimens is performed by gas-gun testing stand by a direct method. The scheme of gas-gun testing stand is shown in Fig. 8. The scheme and dimensions of hat-shaped specimen is shown in Fig. 8.

Geometric parameters of the elements of gas-gun testing stand were described in [5].

Figure 9 shows photographs of specimens after tensile testing by gas-gun testing stand. Failure of specimens is a conical surface of the test portion at an angle from the concentrator is $45^{\circ}$ on the inner surface of the stress to the stress on the concentrator outer surface.

Figures 10-12 show the change of forces in the strain gauge at a distance of $21.66 \mathrm{~cm}$ from the impacted end of the measuring rod (Fig. 10), on the contact surface of the measuring rod - hat-shaped specimen (Fig. 11), in the middle of the test portion (Fig. 12) versus time in the calculation without failure (marked 1) and with failure (2).

Figures 13-14 show effective plastic strains and effective stresses in the times $\mathrm{t}=6,7494 * 10^{-5} \mathrm{~s}$

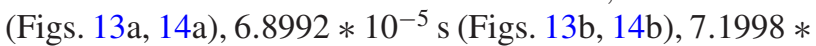
$10^{-5} \mathrm{~s}$ (Figs. 13c, 14c).

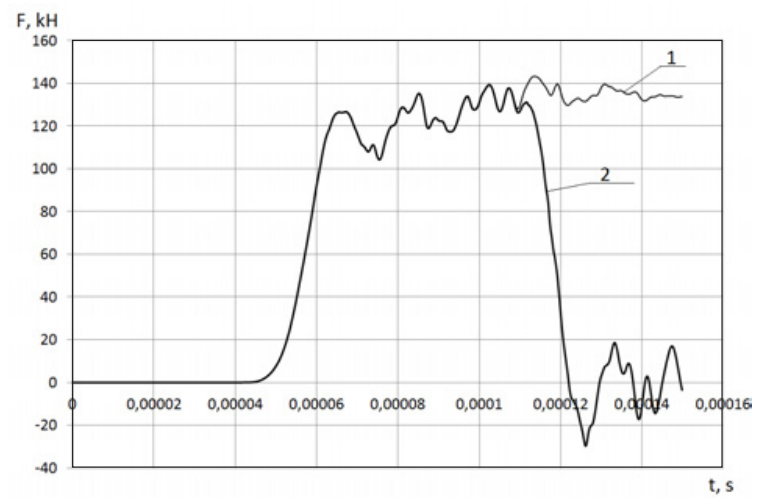

Figure 10. Force in the strain gauge.

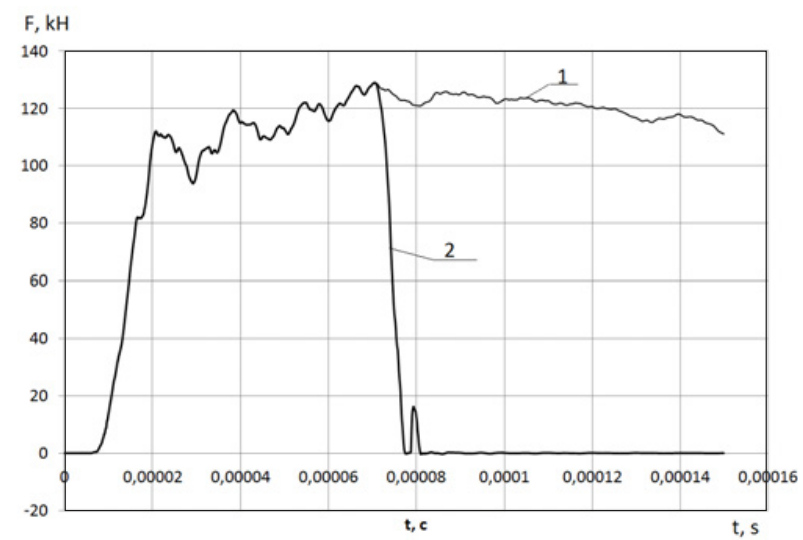

Figure 11. Force on the contact surface of the measuring rod hat-shaped specimen.

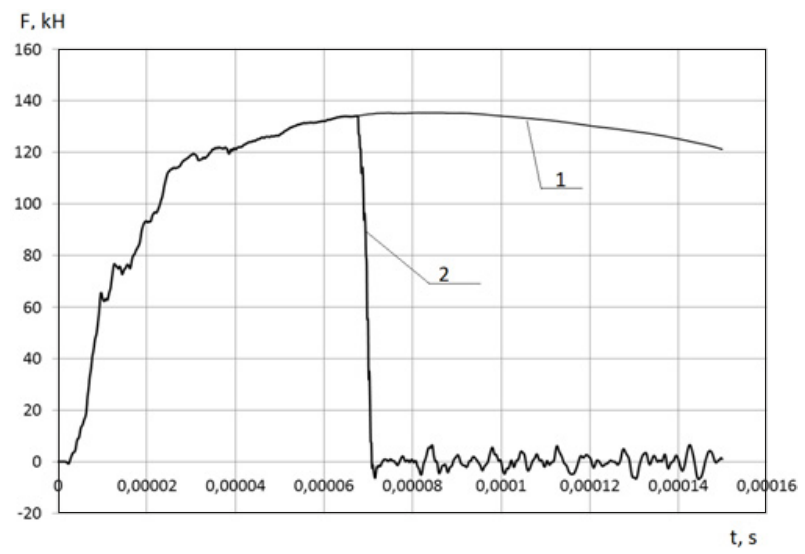

Figure 12. Force in the middle of the test portion.

The maximum intensity of plastic strains of $16 \%$ is used as criterion.

When this criterion is achieved the specimen is destroyed and normal to the failure surface stresses in the element are zero.

Studying of strength parameters of the material using of the hat-shaped specimens have some advantages as compared to solid axisymmetric corset specimens because it allows to implement a wider range of variation of the 


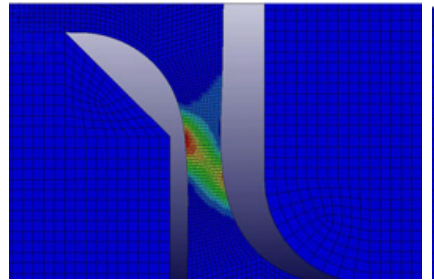

a

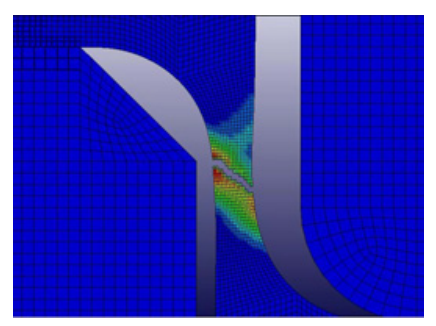

c

Figure 13. Effective plastic strains.

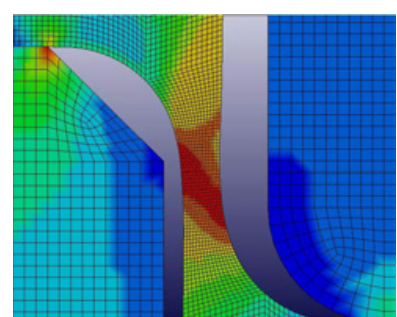

a

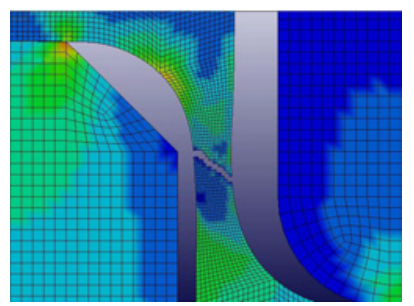

c

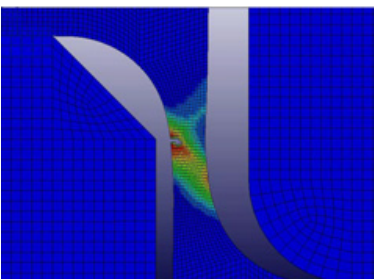

b

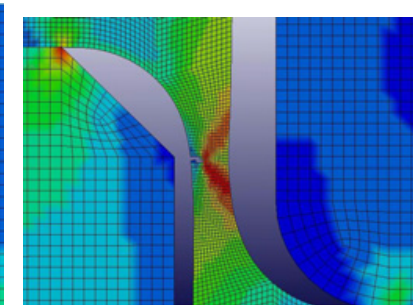

b

Figure 14. Effective stresses.

stress state by varying the thickness and length of the test portion. At low wall thickness of specimen compared to the length of the test portion the stress-strain state is closed to uniaxial. And if there are stress concentrators the stress-strain state volumetric. Volumetric stress state is characterized for corsetry specimens. A viscous and brittle failure can be realized in hat-shaped specimens.

\section{Conclusion}

Numerical and physical simulations of the tensile deformation process of hat-shaped specimens on the vertical gas-dynamic testing stand are done. The influence of the form striker on the tensile deformation process and choose the best form for the realization of experiments on tensile specimens on the gas-gun testing stand by a direct method. A wider range of varying types of the stress-strain state in the study of strength parameters of materials of hat-shaped specimens compared with corset axisymmetric solid specimens is described. Sufficiently high sensitivity of defined experimental parameters is shown in the experimental and theoretical analysis of the stress-strain state of the specimens at the time of destruction by numerical simulation of elastic-plastic deformation and failure of hat-shaped specimens.

The research was financially supported by the Federal Targeted Programme for Research and Development in Priority Areas of Development of the Russian Scientific and Technological Complex for 2014-2020 under the contract 14.578.21.0036 (unique identifier RFMEFI57814X0036).

\section{References}

[1] U.S. Lindholm, L.M. Yeakley Exp. Mech. 8, 1 (1968)

[2] D. Mohr, G. Gary J. Phys. IV 134 (2006)

[3] T. Nicholas Exp. Mech. 21, 5 (1981)

[4] J. R. Klepaczko Trends in Mechanics in Materials / eds. W.K. Novacki, J.R. Klepaczko. Warsaw (2001)

[5] V.G. Bazhenov, M.S. Baranova, E.V. Nagornykh Hopkinson Centenary Conference, Cambridge, UK, September 9-11, Fraunhofer EMI, Freiburg, Germany (2014)

[6] V.G. Bazhenov, S.V. Zefirov, A.V. Kochetkov, Problems of strength and plasticity. Research and optimization of constructions. Gorkovsky university, 4-13 (1987)

[7] V.Y. Lavrinenko, V.G. Bazhenov, E.V. Pavlenkova High Tech in mechanical engineering, No 5 (23) (2013) 